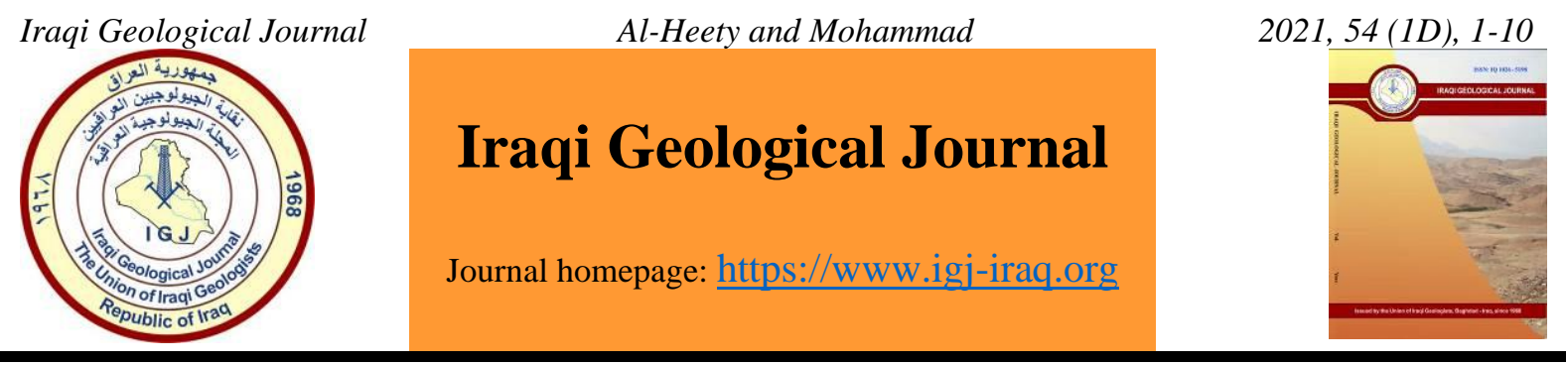

\title{
The Reliance of the Earthquake B-Value on Depth and Focal Mechanism
}

\author{
Emad Abdulrahman Al-Heety ${ }^{1, *}$ and Osama J. Mohammad ${ }^{1}$ \\ ${ }^{1}$ Department of Applied Geology, College of Science, University of Anbar, Ramadi, Iraq \\ *Correspondence: emadsalah@uoanbar.edu.iq
}

Received: 21 July 2020; Accepted: 25 January 2021; Published :30 April 2021

\begin{abstract}
The earthquake size distribution (b-value) is a significant factor to recognize the seismic activity, seismotectonic, and seismic hazard assessment. In the current work, the connection of the b-constant value with the focal depth and mechanism was studied. The effect of the study scale (global, regional and local) on the dependence of bvalue on the focal mechanisms was investigated. The database is quoted from the Global Centroid Moment Tensor catalog. The selected earthquakes are the shallow normal, reverse and strike-slip events. The completeness magnitude (Mc) is 5.3. The maximum likelihood method is utilized to compute the b-value. The obtained results show that the b-value is decreasing with depth to range $10-20 \mathrm{~km}$, then increases to the depth of $40 \mathrm{~km}$. The turning point of $b$-value (increasing of b-value) locates at the depth of the transition brittle-ductile zone. Globally and regionally, low, moderate, and high b-values are associated with reverse, strike-slip, and normal focal mechanisms, respectively, while locally, the relation between b-values and focal mechanisms shows different association trends, such as low, moderate, and high b-values are associated with normal, strike-slip, and reverse focal mechanisms and so on.
\end{abstract}

Keywords: b-value; Focal depth; Focal mechanisms; Maximum likelihood

\section{Introduction}

The earthquake-magnitude distribution follows the Gutenberg-Richter power law (Gutenberg and Richter, 1944). This distribution is described by $\log _{10} \mathrm{~N}=\mathrm{a}-\mathrm{bM}$, where $\mathrm{N}$ is the total number of earthquakes with magnitude $\geq M$, and $a, b$ are constants. The a-constant indicates the total number of earthquakes, and the b-constant (b-value) describes the frequency of earthquake size distribution. The dependence of $b$-value on depth has attracted the attention of many seismologists. Gutenberg and Richter (1944) investigated the depth variation of the b-value. They found that the b-value of shallow events is less than $b$-value of intermediate and deep events. After the pioneering work of Gutenberg and Richter, many authors showed that the b-constant value reduces with depth (Evernden, 1970; Wyss, 1973; Mori and Abercrombie, 1997; Gerstenberger et al. 2001; Zhu et al. 2005; Popandopouls and Lukk, 2014, Spada et al. 2013; Al-Heety 2011; Rigo et al., 2018). Wyss et al. (2008) found that b-constant value rises with the increasing of the earthquake's depth. Other authors discussed the reliance of b-value on depth from a statistical point of view. Variation of b-value is often statistically insignificant and that the lowering of b-constant value with depth should be explained with care (Amorese et al. 2010). The bvalue variation can be interpreted as the artifact arising due to the absence of statistical significance (Del Pezzo et al., 2003). The dependence of b-constant value on depth value was investigated locally and/or

DOI: 10.46717/igj.54.1D.1Ms-2021-04-21 
regionally, in California/USA (Mori and Abercrombie, 1997; Grestenberger et al. 2001; Wyss et al. 2008; Amorese et al. 2010), in Beijing area/ China (Zhu et al. 2005), in Garm, Tajikistan (Lukk and Popandopulos, 2012; Popandopoulos and Lukk, 2014), in Koyna-Warna region / India (Singh and Chadha, 2010), in regions of Iceland and Japan (Wyss et al. 2008), in Pyrenees/France (Rigo et al. 2018), in Abu Dabbab area, Red Sea (Abu El-Nader et al. 2016) and in Taiwan (Hui et al. 2020). Globally, the reliance of $b$ - constant value on focal depth in the continental seismicity regions was achieved by $\mathrm{Al}$ Heety (2011). The reliance of b-constant value on the fault plane solutions was discussed locally and/or regionally, in California and Japan by Schorlemmer et al. (2005), in Japan by Ishibe et al. (2008), in Italy by Gulia and Wiemer (2010), and in India by Bora et al. (2018). Based on the global scale, AlHeety and Al Esho (2019) studied the relationship of b-constant value with faulting type. Regardless of the study scale, the previous studies showed a low b- constant value in reverse faulting regions, a moderate in strike-slip faulting regions, and a high $b$-value in normal faulting regions. There are two reasons motivate us to conduct this study: (1) the lack of studies related to the relationship of b- constant value with focal mechanism on a global scale and (2) ambiguity of the observed relationship between b-value and depth. The aims of this study are to investigate (1) the dependence of b-value on the focal depth and the focal mechanism, and (2) does the focal mechanism effect on the connection of b-constant value with the depth of earthquakes.

\section{Data and Methodology}

The earthquakes catalog of this study was quoted from the Global Centroid Moment Tensor (GCMT) Catalog, from 1976 to 2018. Earthquakes with magnitude $M \geq 5.1$ and depth of $0-70 \mathrm{~km}$ were selected in this study, (Fig. 1). The earthquake catalog completeness magnitude (Mc) is estimated using the maximum curvature method introduced by Wiemer and Wyss (2000) methodology. The correct estimation of the values of $\mathrm{a}$ and $\mathrm{b}$ constants requires the calculation of the earthquake catalog's completeness (Woessner and Wiemer, 2005).

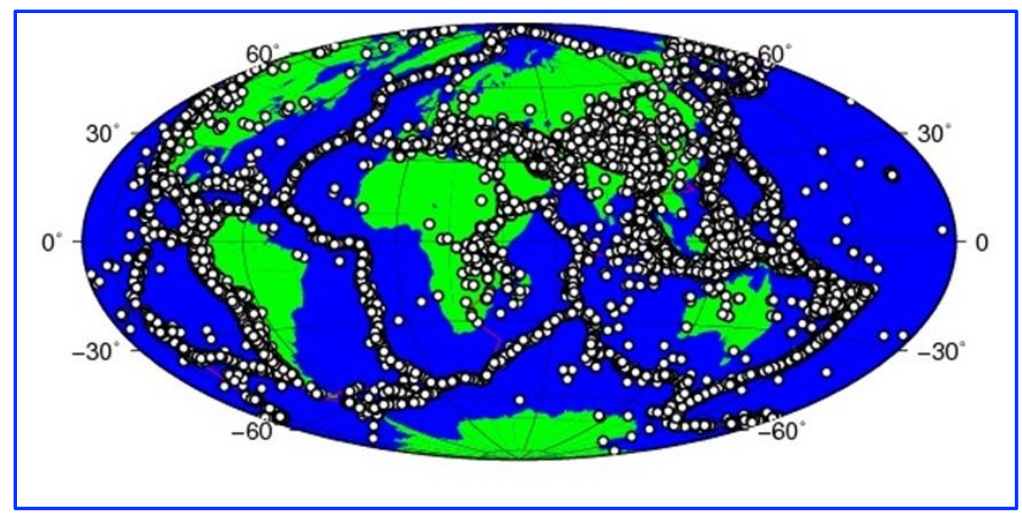

Fig.1. Spatial distribution of the shallow earthquakes $(M \geq 5.1)$ for the period 1976-2018

To investigate the dependence of b-value on the focal mechanism, we sorted the selected earthquakes based on the rake of slip of fault plane into three types of focal mechanism: normal, reverse, and strike-slip faulting mechanism. The spatial and earthquake magnitude distribution for each class are shown in Figs. 2 and 3, respectively. The b-value and its uncertainty are calculated using the following maximum likelihood method (Aki, 1965):

$$
b=\frac{0.4343}{(\text { Mmean }-M c)}
$$

$\mathrm{M}_{\text {mean }}$ is the mean of magnitudes and $\mathrm{M}_{\mathrm{c}}$ is the completeness magnitude. Uncertainty about the value of b- constant has been calculated by the following equation:

$$
\mathrm{ab}=\mathrm{b} / \sqrt{ } \mathrm{N}
$$

Where $\mathrm{N}$ is the number of earthquakes. 


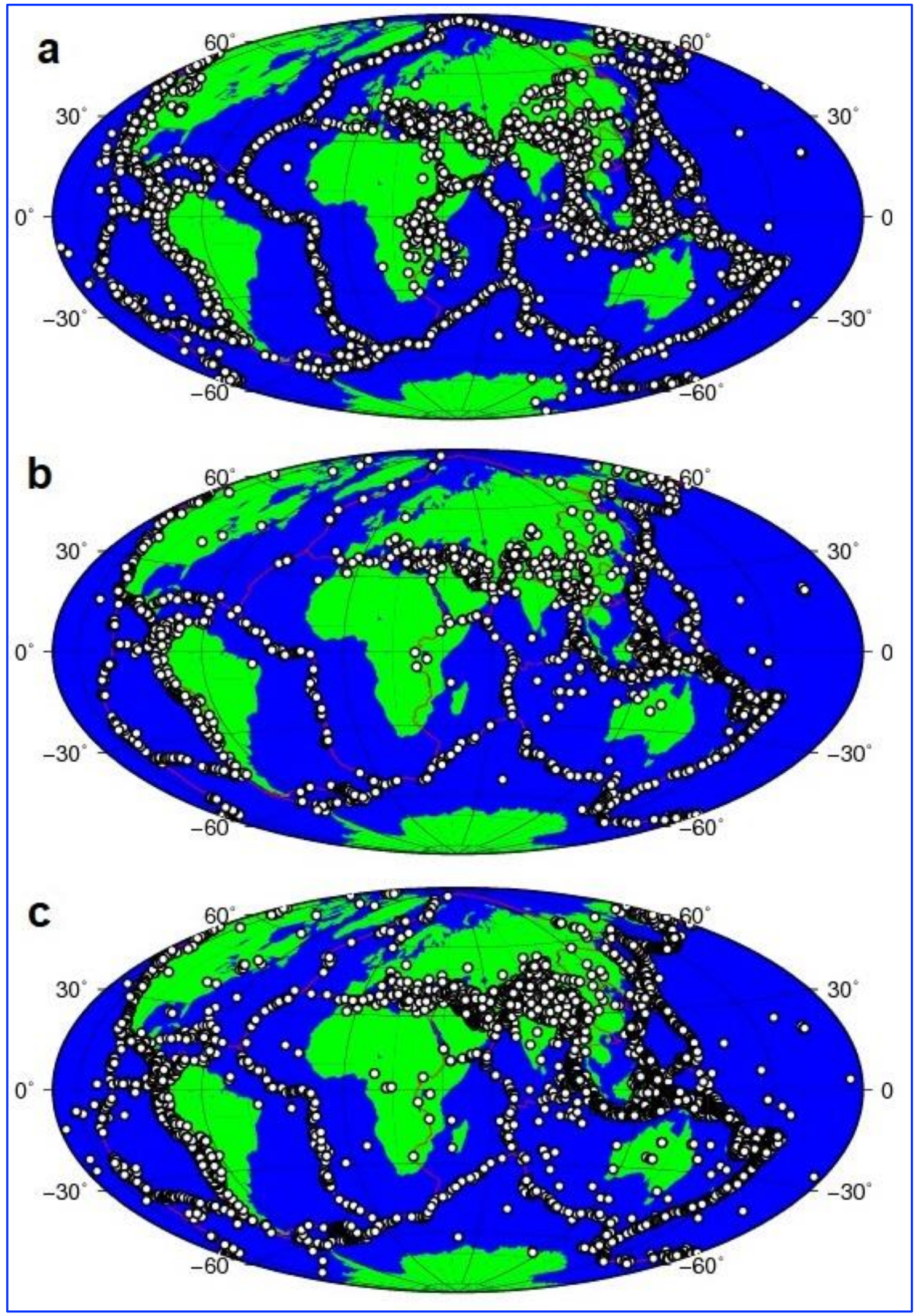

Fig. 2. Spatial distribution of (a) the normal, (b) strike-slip and (c) reverse faulting earthquakes for the period $1976-2018$ 


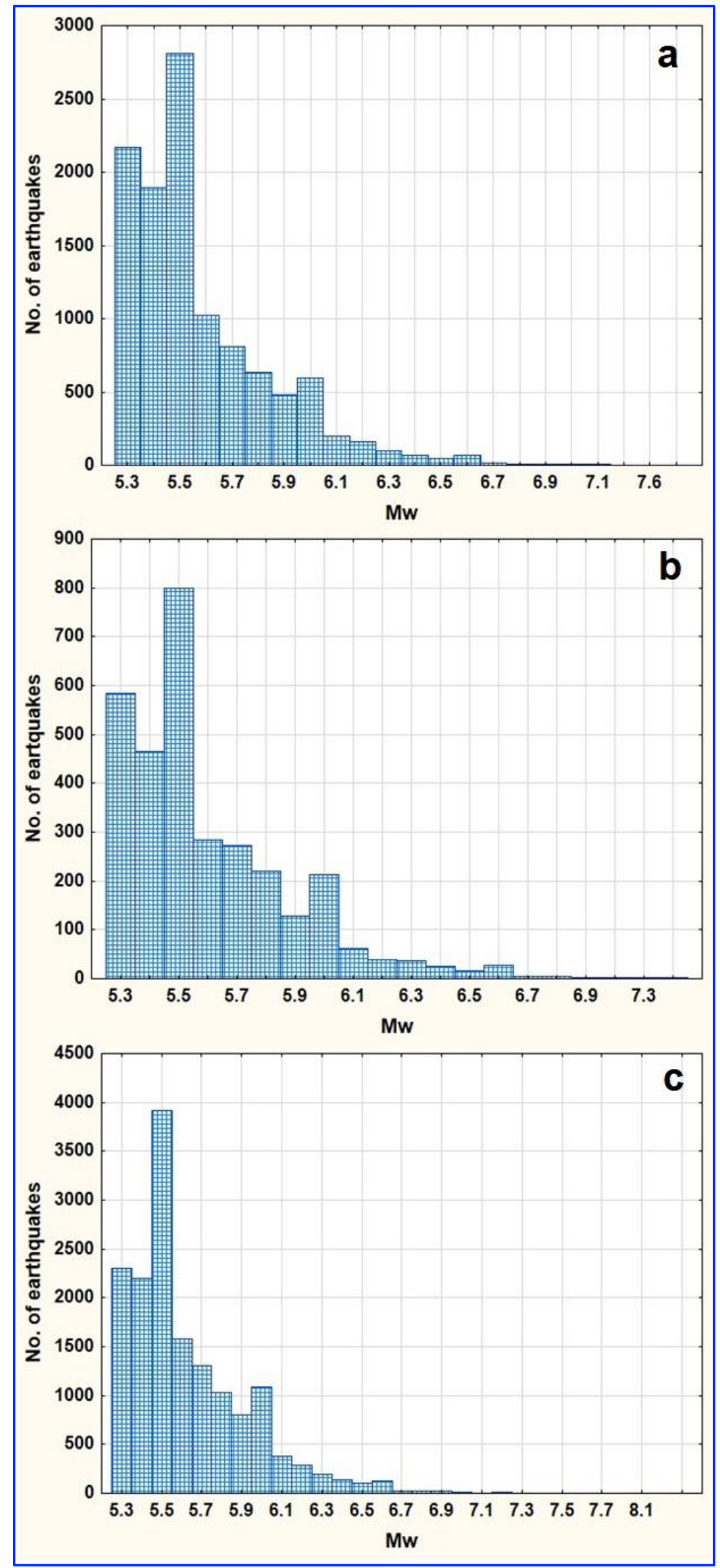

Fig. 3. The number of earthquakes as function of magnitude for (a) normal, (b) strike-slip and (c) reverse faults The completeness magnitude $\mathrm{M}_{\mathrm{c}}$ is 5.3 for reverse, strike-slip and normal faulting events, are presented in Fig. 4. 


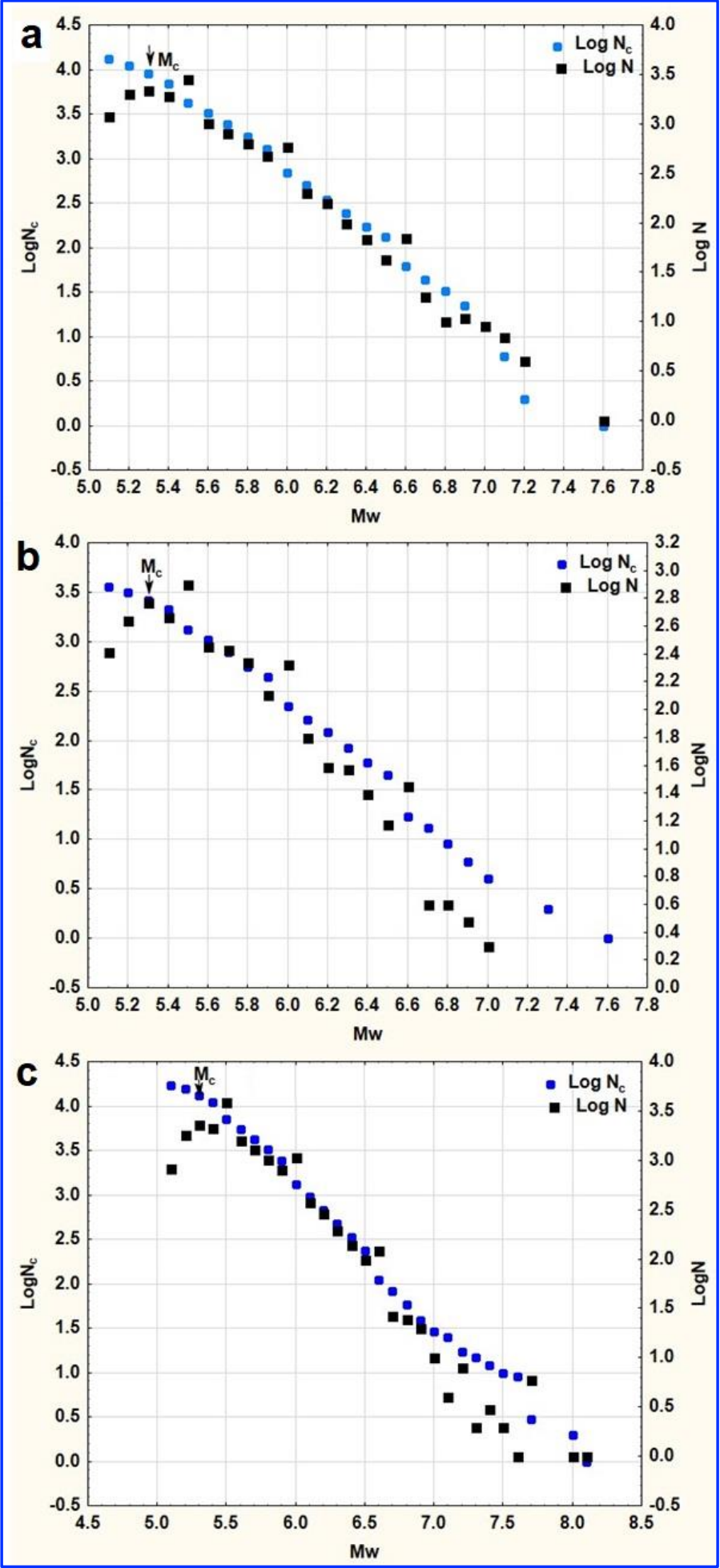

Fig. 4. The completeness magnitudes of the (a) normal, (b) strike-slip and (c) reverse faulting earthquakes

\section{Results and Discussion}

\subsection{The Relation Between the B-Value and The Depth}

Results of variation of b-value in magnitude-frequency relation of all events, normal faulting events, reverse faulting events and strike-slip events as function of depth are listed in Table 1. The remarkable trend in the reliance of b-value on depth is the decreasing in b-constant value at depth about 
$10 \mathrm{~km}$ and increasing after that depth for all shallow, normal faulting, and strike-slip events, while the b-value of reverse faulting events decreases at depth of about $20 \mathrm{~km}$ and then increases beyond that. Beneath the depth of about $10 \mathrm{~km}$, the b-value increases with depth and reaches the highest value at depth of about $35 \mathrm{~km}$ and $45 \mathrm{~km}$ for strike-slip and normal faulting events, respectively, and then the bvalues fluctuates up and down. For the reverse faulting events, the b-value increases below the depth of about $20 \mathrm{~km}$ with the increasing of the focal depth to the maximum value at a depth of about $35 \mathrm{~km}$ and after this depth the b-value fluctuates down and up. All used shallow events show maximum b-value at depth of about of $12 \mathrm{~km}$ and decreases at depth of about $18 \mathrm{~km}$ and then increases with increasing depth and the highest value is at depth of about $35 \mathrm{~km}$. Beneath the depth of $35 \mathrm{~km}$, the b-value oscillates up and down, for example, the b-value increases at depth of about $40 \mathrm{~km}$ and decreases at depth of $45 \mathrm{~km}$, and so on. The obtained result shows decreasing in b-constant value up to $10 \mathrm{~km}$ followed by an increase. This result is in good agreement with the b-value reported in California (Mori and Abercrombie 1997), in Beijin area, China (Zhu et al. 2005), in Koyna-Warna, India (Singh and Chadha, 2010), and in Pyrenees (Rigo etal. 2018). In the current study, we find that the b-constant value in the lower crust is more than in the upper crust.

Table 1. b-constant value as function of depth

\begin{tabular}{|c|c|c|c|c|c|c|c|c|}
\hline \multirow{3}{*}{$\begin{array}{c}\begin{array}{c}\text { Depth } \\
(\mathbf{K m})\end{array} \\
0-5\end{array}$} & \multicolumn{8}{|c|}{ b-constant value } \\
\hline & \multicolumn{2}{|c|}{$\begin{array}{l}\text { Normal faulting } \\
\text { earthquakes }\end{array}$} & \multicolumn{2}{|c|}{$\begin{array}{c}\text { Reverse faulting } \\
\text { earthquakes }\end{array}$} & \multicolumn{2}{|c|}{$\begin{array}{c}\text { Strike-slip faulting } \\
\text { earthquakes }\end{array}$} & \multicolumn{2}{|c|}{ All earthquakes } \\
\hline & 1.50 & \pm 0.143 & 1.40 & \pm 0.149 & 1.11 & \pm 0.214 & 1.40 & \pm 0.093 \\
\hline $5-10$ & 1.03 & \pm 0.049 & 1.14 & \pm 0.055 & 0.99 & \pm 0.095 & 1.09 & \pm 0.034 \\
\hline $10-15$ & 1.06 & \pm 0.047 & 1.11 & \pm 0.046 & 0.94 & \pm 0.087 & 1.04 & \pm 0.017 \\
\hline $15-20$ & 1.28 & \pm 0.061 & 1.03 & \pm 0.040 & 1.11 & \pm 0.103 & 1.11 & \pm 0.031 \\
\hline $20-25$ & 1.36 & \pm 0.064 & 1.03 & \pm 0.036 & 1.17 & \pm 0.101 & 1.14 & \pm 0.030 \\
\hline $25-30$ & 1.55 & \pm 0.079 & 1.17 & \pm 0.040 & 1.36 & \pm 0.108 & 1.28 & \pm 0.034 \\
\hline $30-35$ & 1.74 & \pm 0.087 & 1.28 & \pm 0.042 & 1.50 & \pm 0.145 & 1.36 & \pm 0.015 \\
\hline $35-40$ & 1.97 & \pm 0.083 & 1.55 & \pm 0.040 & 1.61 & \pm 0.119 & 1.61 & \pm 0.034 \\
\hline $40-45$ & 1.67 & \pm 0.098 & 1.32 & \pm 0.046 & 1.61 & \pm 0.149 & 1.40 & \pm 0.040 \\
\hline $45-50$ & 1.55 & \pm 0.105 & 1.36 & \pm 0.049 & 1.81 & \pm 0.176 & 1.45 & \pm 0.044 \\
\hline $50-55$ & 1.36 & \pm 0.106 & 1.55 & \pm 0.063 & 1.50 & \pm 0.149 & 1.50 & \pm 0.050 \\
\hline $55-60$ & 1.55 & \pm 0.120 & 1.40 & \pm 0.063 & 1.74 & \pm 0.192 & 1.45 & \pm 0.053 \\
\hline $60-65$ & 1.55 & \pm 0.118 & 1.61 & \pm 0.080 & 1.32 & \pm 0.156 & 1.55 & \pm 0.060 \\
\hline $65-70$ & 1.24 & \pm 0.097 & 1.45 & \pm 0.079 & 1.32 & \pm 0.153 & 1.36 & \pm 0.056 \\
\hline
\end{tabular}

A high b-values were observed in the lower crust of Shilling Plateau, India (Khan and Chakraborty, 2007), and in Garm Region of Tajikistan (Popandopoulos and Lukk ,2014). The point at which the b-constant value changes is called the inflection point. In our current study, we find that the depth of the inflection point of b-value ranges from 10 to $20 \mathrm{~km}$. The inflection point of b-value in Italy, Greece, Turkey, and Japan is at depth of 15km, in Swiss foreland at depth of $25 \mathrm{~km}$ (Spada et al. 2013), and at depth of 15-16 km in Garm Region of Tajikistan (Popandopoulos and Lukk, 2014). We agree with the interpretation proposed by a number of authors which states that the inflection point depth of b-value is interpreted as depth of brittle-ductile transition BDT (Spada et al. 2013; Popandopoulos and Lukk, 2014; Dolioni et al. 2011, 2015; Petricca et al. 2015, Rigo et al. 2018). We can also interprete the inflection point depth of b-constant value in terms of the depth of the Conrad discontinuity, particularly in the continental crust regions. Conrad discontinuity is not related to the change in the chemical composition from granitic to basaltic rocks, but to change in the physical state of the rock from brittle 
to ductile (Zhamaletdinov, 2014). We can make the conclusion that the BDT is associated with the Conrad discontinuity.

\subsection{Reliance of B-value on Focal Mechanisms}

Results of the reliance of b-value on the focal mechanisms are listed in Table 2. The remarkable trend of $b$-value and its relation with the focal mechanism of earthquakes is in the following descending order: b-normal focal mechanism > bstrike-slip focal mechanism > breverse focal mechanism. The high b-value of the normal faulting events may be interpreted in terms of that the maximum volume comprised by these earthquakes is smaller than the strike-slip and reverse events, being the activated fault mostly about three times the focal depth (Doglioni et al. 2015). The differential stress is inversely proportional to the $b$-constant value in the continental crust. The high $b$-constant values associate with the low differential stress whereas the low b-constant values correlate with the high differential stress. The potential reliance of b-constant value on focal mechanism was investigated in different regions. In California and Japan, the reverse faulting earthquakes have the lowest b- constant values, the strike-slip earthquakes the moderate values and normal faulting earthquakes the highest values (Schorlemmer et al. 2005). They inferred that the b-value acts as a stress meter that depends inversely on differential stress. The relation between b- constant value and faulting style was investigated in Italy (Gulia and Wiemer, 2010). They found that the lowest b-values are obtained for reverse faulting, highest for normal, followed by the strike-slip. In Indo-Burma ranges of northeast India, the b-constant has high value in normal faulting regions, the moderate value in strike-slip faulting regions, and low value in reverse faulting regions (Bora et al. 2018). In a young orogenic belt in Taiwan, the b-value of normal faulting events is higher than of the strike-slip faulting events, which in turn is higher than the reverse faulting events (Wu et al., 2018). The reverse and normal faulting areas of the subduction zone in Mexico, have low and high b- values, respectively (Rordríguez-Pérez and Zuũiga 2018). On a global scale, Al-Heety and Al Esho (2019) and Al-Heety (2020) found that reverse, strike-slip and normal faulting earthquakes happen in regions of low, moderate, and high b-value, respectively. The results of the current study are consistent with the results of the previous studies mentioned above.

\subsection{Effect of Study Scale on The Relation Between B-Value and Focal Mechanisms}

To investigate the effect of using different study scales on the relationship between $b$-value the focal mechanism types, the b-values for the three focal mechanism types were calculated globally, regionally and locally, Table 2. Globally and regionally, the remarkably trend of the b-value in its relation to the focal mechanisms is: $\mathrm{b}$ normal mechanism $>\mathrm{b}$ strike-slip mechanism $>\mathrm{b}$ reverse mechanism. The b-values calculated based on the local scale show different patterns. For example, in Fiji, Solomon and South Sandwich Islands Regions, the order of $b$-value is $b$ reverse mechanism $>b$ strike-slip mechanism $>$ b normal mechanism. In Kuril and Vanuatu Islands, the b normal mechanism $>b$ reverse mechanism $>b$ strike-slip mechanism. The obtained $b$-values of the events occurred in Tonga Islands show that $b$ strike-slip mechanism is more than $b$ reverse mechanism which in turn is greater than $b$ normal mechanism. The different patterns mentioned above can be explained in the context of the effect of the ratio of the larger magnitude earthquakes to the smaller magnitude and the prevailing tectonic environment, extentional (normal mechanism), compressional (reverse mechanism), and shearing (strike-slip mechanism). There is an inverse relationship between the b-value and the ratio of the number of larger magnitudes to number of the smaller magnitude earthquakes. The higher b-value is the lower ratio of the larger magnitude to smaller magnitude earthquakes and vice versa. We postulate that the scale of study affects the connection tends between the b-constant value and the focal mechanisms as mentioned above. For example, the study based on the global and regional scales showed a connection trend as follows: $\mathrm{b}$ normal mechanism $>$ b strike-slip mechanism $>$ b reverse mechanism, 
while the connection trend resulting from a local study is shown as follows: $b$ reverse mechanism $>b$ strike-slip mechanism > b normal mechanism.

Table 2. b-value and focal mechanisms based on different scales

\begin{tabular}{lccc}
\hline Scale & \multicolumn{3}{c}{ b-value } \\
\hline & $\begin{array}{c}\text { Normal focal } \\
\text { mechanism }\end{array}$ & $\begin{array}{c}\text { Strike-slip focal } \\
\text { mechanism }\end{array}$ & $\begin{array}{c}\text { Reverse focal } \\
\text { mechanism }\end{array}$ \\
Global & $1.61 \pm 0.015$ & $1.50 \pm 0.027$ & $1.36 \pm 0.011$ \\
Regional (Northern hemisphere) & $1.61 \pm 0.022$ & $1.50 \pm 0.040$ & $1.32 \pm 0.015$ \\
Regional (Southern hemisphere) & $1.61 \pm 0.021$ & $1.50 \pm 0.036$ & $1.40 \pm 0.016$ \\
Regional(Eastern hemisphere) & $1.55 \pm 0.019$ & $1.40 \pm 0.031$ & $1.32 \pm 0.013$ \\
Regional (western hemisphere) & $1.67 \pm 0.026$ & $1.74 \pm 0.052$ & $1.45 \pm 0.020$ \\
Local(Fiji Islands Regions) & $1.50 \pm 0.135$ & $1.97 \pm 0.232$ & $2.17 \pm 0.283$ \\
Local(Kuril Islands) & $1.24 \pm 0.153$ & $0.92 \pm 0.107$ & $1.17 \pm 0.050$ \\
LocalSouth Sandwich $\quad$ Islands & $1.67 \pm 0.175$ & $1.74 \pm 0.243$ & $1.81 \pm 0.123$ \\
Regions & $1.14 \pm 0.096$ & $1.14 \pm 0.120$ & $1.21 \pm 0.049$ \\
LocalSolomon Islands & $1.45 \pm 0.095$ & $1.50 \pm 0.168$ & $1.50 \pm 0.066$ \\
LocalTonga Islands & $1.50 \pm 0.116$ & $1.21 \pm 0.176$ & $1.36 \pm 0.063$ \\
LocalVanuatu Islands & & &
\end{tabular}

\section{Conclusions}

We have investigated variations of $b$ constant value of the earthquake's frequency-magnitude relation with the focal depth and the focal mechanisms. From the obtained results, we draw the following conclusions:

- Golablly, the inflection point depth of b-constant value ranges from 10 to $20 \mathrm{~km}$. This depth is interpreted as depth of the brittle-ductile transition.

- The brittle - ductile transition may be associated with the depth Conrad discontinuity that related with change in the physical properties of the upper granitic layer and lower basaltic layer

- Based on global and regional scales, high b-value is associated with normal focal mechanism, intermediate b-value with strike-slip focal mechanism, and low b-value with the reverse focal mechanism. The b-values calculated based on the local scale show different patterns of the connection between the $b$-value and the focal mechanisms.

- The study scale (globally, regionally and locally) may affect the relation trend between b-value and the focal mechanisms.

\section{Acknowledgments}

The authors are very grateful to the Editor in Chief Prof. Dr. Salih M. Awadh, the Secretary of Journal Mr. Samir R. Hijab. and the Technical Editors for their great efforts and valuable comments.

\section{References}

Abu El-Nader, I., Shater, A., Hussein H., 2016. Mapping b-values beneath Abu Dabbab from June to August 2004 earthquake swarm. Journal of Astronomy and Geophysics, 5(2), 403- 4012.

Aki, K., 1965. Maximum likelihood estimates of $b$ in the formula $\log \mathrm{N}=\mathrm{a}-\mathrm{bM}$ and its confidence. Bulletin of Earthquake Research Institute of the University of Tokyo, 43, 237-239.

Al-Heety, E., 2011. Variation of b-value in the earthquake frequency- magnitude distribution with depth in the intraplate regions. International Journal of Basic and Applied Sciences, 11, 29-36.

Al-Heety, E., Al Esho, L., 2019. Faulting Style and b-Value: A Global Perspective. N. Sundararajan et al. (eds.), On Significant Applications of Geophysical Methods, Advances in Science, Technology and Innovation. 
Al-Heety, E., 2020. New updated classification of shallow earthquakes based on faulting style. Iraqi Journal of Science, 61, 103-111.

Amorese, D., Grasso, J. R., Rydelek, P., 2010. On varying b-values with depth: results from computer-intensive tests for Southern California. Geophysics Journal International, 180, 347-360.

Bora, D., Borah, K., Mahanta, R., Borgohain, J., 2018. Seismic b-values and its correlation with seismic moment and Bouguer gravity anomaly over Indo-Burma ranges of northeast India: Tectonic implications. Tectonophysics, 728-729,130-141.

Del Pezzo, E., Bianco, F., Saccorotti, G., 2003. Duration magnitude uncertainty due to seismic noise: Inferences on the temporal pattern of G-R b-value at Mt. Vesuvius, Italy. Bulletin Seismic Society American, 93, 1847-1853.

Doglioni, C., Barbara, S., Carminati, E., 2011. Role of the brittle-ductile transition on fault activation. Physics Earth Planet International, 184, 161-171.

Doglioni, C., Carminati, E., Riguzzi, F., 2015. Normal fault earthquakes or graviquakes. Scientific Reports |5:12110.

Evernden, J., 1970. Study of regional seismicity and associated problems. Bulletin Seismic Society American, 60, 393-446.

Gerstenberger, M., Wiemer, S., Giardini, D., 2001. A systematic test of the hypothesis that the b-value varies with depth in California. Geophysical Research Letter, 28 (1), 57-60.

Gulia, L., Wiemer, S., 2010. The influence of tectonic regimes on the earthquake size distribution: A case study for Italy. Geophysical Research Letter, 37 (10).

Gutenberg, B., Richter, C., 1944. Frequency of earthquakes in California. Bulletin Seismology Society America 34, 185-188.

Hui, C., Cheng, C., Ning, L., Yang, J., 2020. Multifractal characteristics of seismogenic systems and b values in the Taiwan seismic seismic region. International Journal Geo-Information 9, 384.

Ishibe, T., Tsuruoka, H., Shimazaki, K., 2008. The dependency of the b-value on the focal mechanism and on a hypo central depth. Abstracts of Japan Geoscience Union Meeting, Chiba, Japan, May 25-30, 2008.

Khan, P., Chakraborty, P., 2007. The seismic b-value and its correlation with Bouguer gravity anomaly over the Shillong Plateau area: tectonic implication. Journal of Asian Earth Sciences, 29, 136-147.

Lukk, A., and Popandopoulos, G., 2012. Reliability of determining the parameters of Gutenberg-Richter distribution for weak Earthquakes in Garm, Tajikistan. Izvestiya, Physics of the Solid Earth, 48, 698-720.

Mori, J., Abercrombie, R., 1997. Depth dependence of earthquake frequency -magnitude distributions in California: Implications for rupture initiation. Journal Geophysics Research, 102, 15081-15090.

Petricca, P., Barba, S., Carminati, E., Doglioni, C., Riguzzi, F., 2015. Graviquakes in Italy. Tectonophysics 656, 202-214.

Popandopoulos, G., Lukk, A., 2014. The depth variations in the b-value of frequency-magnitude distribution of the earthquakes in the Garm Region of Tajikistan. Izvestiya, Physics of the Solid Earth, 50, 273-288.

Rigo, A., Souriau, A., Sylvander, M., 2018. Spatial variations of b-value and crustal stress in the Pyrenees. Journal Seismology, 22, 337-352.

Rordríguez-Pérez, Q., Zuũiga, F., 2018. Imaging b-value depth variations within the Cocos and Rivera plates at the Mexican subduction zone. Tectonophysics, 734-735, 33-43.

Schorlemmer, D., Wiemer, S., Wyss, M., 2005 Variations in earthquake-size distribution across different stress regimes. Nature 437, 539-542.

Singh, C., Chadha, R., 2010. Variations in the frequency-magnitude distribution of earthquakes with depth in the Koyna-Wana region, India. Journal Asian Earth Sciences, 39, 331-334.

Spada, M., Tormann, T., Wiemer, S., Enescu, B., 2013. Generic dependence of the frequency-size distribution of earthquakes on depth and its relation to the strength profile of the crust. Geophysics Research Letter, 40, 709-714.

Wiemer, S., Wyss, M., 2000. Minimum magnitude of complete re- porting in earthquake catalogs: examples from Alaska, the Western United States, and Japan. Bulletin Seismic Society American, 90, 859-869.

Woessner, J., Wiemer, S., 2005. Assessing of the quality of earthquakes catalogues: estimating the magnitude of completeness and its uncertainty. Bulletin Seismology Society American, 95, 684-698. 
Wu, Y., Chen, S., Huang, T., Huang, H., Chao, W., Koulakov, I., 2018. Relationship between earthquake b-values and crustal stresses in a young orogenic belt. Geophysics Research Letter, 45 (4), 1832-1837.

Wyss, M., 1973. Towards a physical understanding of the earthquake frequency distribution. Geophysical Journal International, 31 (4), 341-359.

Wyss, M., Pachiani, F., Deschamps, A., Patau, G., 2008. Mean magnitude variations of earthquakes as a function of depth: Different crustal stress distribution depending on tectonic setting. Geophysics Research Letter, 35, L01307.

Zhamaledtinov, A., 2014. The nature of the Conrad discontinuity with respect to the results of Kola superdeep well drilling and the data of a deep geoelectrical survey. Doklady Earth Sciences, 455, 350-354.

Zhu, A., Xu, X., Hu, P., Zhou, Y., Chen, G., Gan, W., 2005. Variation of b-value with hypo central depth in Beijing area: Implications for earthquake nucleation. Chinese Science Bulletin, 50, 691- 695. 